\title{
The Effects of Inhaled Corticosteroids on Growth in Children
}

\author{
Jim Philip ${ }^{*}$
}

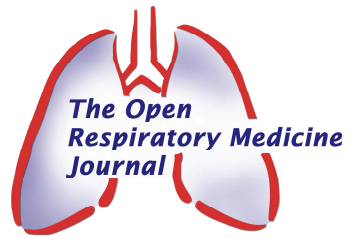

Department of Endocrinology, NMC Hospital, Al Mutradeh area, AL AIN, UAE

\begin{abstract}
Inhaled corticosteroids (ICS) are recommended as the first-line therapy for children with persistent asthma. These agents are particularly effective in reducing underlying airway inflammation, improving lung function, decreasing airway hyper-reactivity, and reducing intensity of symptoms in asthmatics. Chronic diseases, such as asthma, have growth-suppressing effects independent of the treatment, which inevitably complicates growth studies. One year studies showed a small, dose-dependent effect of most ICS on childhood growth, with some differences across various ICS molecules, and across individual children. Some ICS at the doses studied did not affect childhood growth when rigorous study designs were used. Most studies did not conform completely with the FDA guidance. The data on effects of childhood ICS use on final adult height are conflicting, but one recent well-designed study showed such an effect, clearly warranting additional studies. In spite of these measurable effects of ICS on childhood growth, it is important to understand that the safety profile of all ICS preparations, with focal anti-inflammatory effects on the lung, is significantly better than oral glucocorticoids.
\end{abstract}

Keywords: Childhood asthma, inhaled Corticosteroids, linear growth.

\section{INTRODUCTION}

Inhaled corticosteroids (ICS) have proved effective in the treatment of asthma over the past several decades. Current guidelines for asthma management recommend low-dose ICS as first-line therapy for patients with mild persistent asthma and medium-dose ICS or combination therapy with long-acting beta2-agonists as the preferred therapy for moderately severe asthma [1]. ICS reduce airway inflammation and hyper-responsiveness, decrease symptom severity, and prevent or reduce the occurrence of acute asthma exacerbations. Corticosteroids are effective in the treatment of asthma because of their ability to alter with multiple pathways involved in the inflammatory process $[2$, 3]. The histological abnormalities that are typical of asthma have been shown to diminish in the airway biopsy specimens, from patients with asthma who have had treatment with ICS. The changes included fewer mast cells, eosinophils and $\mathrm{T}$ lymphocytes, in the mucosa and submucosa [4], reduced goblet-cell hyperplasia [5], and decreased vascularity [6].

ICS were developed to target their delivery in to the lungs, to reduce the systemic side effects associated with oral corticosteroids. ICS are usually tolerated well at the recommended doses [7]. However, systemic side effects such as disruption of hypothalamic-pituitary-adrenal (HPA) axis function, bone turnover, osteoporosis, and growth suppression may occur with the use of ICS [8]. Corticosteroids are potent inhibitors of linear growth, exerting various effects at various levels of growth axis [9].

*Address correspondence to this author at the Department of Endocrinology, NMC Hospital, Al Mutradeh area, AL AIN, UAE;

Tel: +97137030300; E-mail: drjimphilip@hotmail.com
Blunting of pulsatile growth hormone release, inhibition of insulin-like growth factor-1 bioactivity, osteoblast activity and suppression of collagen synthesis and adrenal androgen production are all known mechanisms by which corticosteroids can inhibit growth. Glucocorticoids also inhibit intestinal calcium absorption, increase urinary calcium excretion and promote bone resorption, all of which can negatively impact bone formation and growth. Exogenous corticosteroid in excess of normal physiological requirements can suppress childhood growth.

However, it should be kept in mind that chronic diseases, such as asthma, have growth-suppressing effects by itself and that this can confound studies of ICS on growth. Mechanisms underlying this effect remain obscure, but a growth-suppressing influence of endogenous cytokines and glucocorticoids produced in response to illness and inflammation appear likely. Any resulting delay in the growth process is associated with delays in pubertal development and pronounced growth deceleration in late childhood [10]. In a prospective long-term cohort study of 82 pre-pubertal steroid-naïve asthmatic patients aged 3 years and above, height/age and weight/age $\mathrm{Z}$ scores were calculated every three months. A multivariate analysis of the final model showed that severe persistent asthma was associated with a lower height for age $Z$ score $(p=0.04)$ [11].

The systemic side effects associated with ICS may cause reluctance among some physicians and patients to use ICS, especially at higher doses and for longer periods that may be required to control more severe and persistent asthma symptoms $[12,13]$. Therefore, it is appropriate to carefully examine the possible effects of ICS on childhood growth. 


\section{FACTORS INFLUENCING THE BIOAVAILABILITY OF ICS}

Inhaled corticosteroids on inhalation, a significant portion of the dose is deposited in the mouth and pharynx, which if not rinsed out of the mouth, may be swallowed and subsequently absorbed from the gastrointestinal tract [14]. The portion of the drug that escapes inactivation by first pass metabolism in the liver enters the systemic circulation unchanged, causes systemic side-effects [15]. The portion of the ICS dose that is delivered to the lungs exerts the desired pharmacological effect. Also a significant portion of the dose that reaches the airways, can subsequently be absorbed into the general circulation, where it can cause systemic sideeffects.

Pharmacokinetic and pharmacodynamic properties of ICS such as bioavailability, lipid conjugation, protein binding, and clearance from systemic circulation can contribute to the systemic side effects [16]. ICS used in asthma are budesonide (BUD), mometasone furoate (MF), fluticasone propionate (FP), beclometasone dipropionate (BDP), ciclesonide (CIC) and Flunisolide (FLU). The particle size of the inhaled steroid molecule is an important determinant of the proportion of ICS that is deposited in the lower airways. The smallest airways have an internal perimeter of $\leq 2 \mathrm{~mm}$ [17]. A particle of $<5 \mathrm{~mm}$ is more likely to be deposited in bronchi and bronchioles whereas particles of $\geq 5 \mathrm{~mm}$, are often deposited in the mouth and throat [18]. Larger particles $(>5 \mathrm{~mm})$, which are deposited in the oropharyngeal cavity, can cause oral candidiasis and hoarseness [19-21]. The particle size, has important bearing on the efficacy and safety profiles of ICS. Particle size distribution differs significantly between currently available ICS formulations [22-25]. Among the ICS, FP delivered by dry-powder inhaler (DPI)), has the largest mass median aerodynamic diameter (MMAD; $\geq 6 \mathrm{~mm}$ ), followed by budesonide DPI $(\geq 2.5 \mathrm{~mm})$. CIC and BDP delivered by hydrofluoroalkane (HFA) metered-dose inhaler (MDI), as solution aerosol formulations, have the smallest particle sizes (MMAD of $\leq 2 \mathrm{~mm}$ ). The particle size of the MF formulation used in the HFA-MDI is not known. Because of the detrimental effects of CFCs on the ozone layer, formulations of ICS in solution and suspension with HFA propellant have gradually replaced chlorofluorocarbon (CFC) formulations. HFA solution aerosol formulations (e.g. BDP, FLU and CIC) exist as extra-fine aerosols that penetrate more effectively into the peripheral lung, whereas HFA suspension formulations (e.g. FP and MF) retain the same particle size and lung deposition as the CFC formulations [26]. In a study of BDP-HFA and BDP-CFC, $55-60 \%$ of the BDP-HFA dose (ex-actuator) was deposited in the lungs, with $29-30 \%$ deposited in the oropharynx [27]. In contrast, deposition of the BDP-CFC dose was $4-7 \%$ in the lungs and $90-94 \%$ in the oropharynx. In another study, lung deposition of FP-CFC was $12-13 \%$, with $72-78 \%$ deposited in the oropharynx [28]. The ciclesonide HFA-MDI delivers small particles (MMAD of 1.1-2.1 mm) and achieves delivery of $50 \%$ of the inhaled exactuator CIC dose to the lung $34 \%$ in the peripheral airway, $36 \%$ in the middle airway and $30 \%$ in the central airway) in healthy subjects [29]. Similar results were obtained in asthmatic patients [32]. This minimises the oropharyngeal deposition of CIC to $39 \%$, which is a advantage over other ICS [29, 30].

Limited oral bioavailability is advantageous of ICS as systemic side effects can be relatively low. The oral bioavailability of currently available ICS varies widely, from $1 \%$ for CIC, MF and FP, to $26 \%$ for beclomethasone monopropionate (BMP) [31-38]. The lipophilicity of an ICS, helps the passage of the drug through the phospholipid bilayer of cell membranes. This correlates positively with the pulmonary retention time and volume of distribution of the drug [39]. The lipophilicity of ICS and the active metabolites varies widely: CIC relative lipophilicity (4.0), FP (3.2), MF (2.0), des-CIC (2.5) and BUD (1) [40].

Protein-binding of ICS can occur and varies from 71$99 \%$ among currently available ICS [34,37-39,41-44]. The degree of protein-binding controls their unbound systemic concentrations and limits their systemic side-effects, since only the free drug is pharmacologically active. So high protein-binding of an ICS effectively reduces the potential for systemic side-effects. Both CIC and des-CIC are highly protein-bound $(99 \%)$ in the systemic circulation, thereby reducing systemic exposure to des-CIC and resulting in minimal cortisol suppression [40].

\section{EFFECTS OF ICS ON GROWTH}

Short-term (weeks) effects of ICS on growth are assessed by monitoring, linear lower-leg growth rate with a Valk knemometer. Knemometry is very sensitive and can detect changes in lower-leg growth rates up to $0.1 \mathrm{~mm}$ [45]. However, knemometry has its limitations. Short-term lower leg growth rates, can not be extrapolated to intermediate or long-term growth, and are therefore relatively inaccurate to predict final height. Long-term effects $(\geq 1$ year) of ICS on growth are assessed using stadiometry by measuring statural height with a Harpenden stadiometer. Stadiometry over longer periods ( $\geq 1$ year) may represent the most appropriate means of evaluating the long-term effects of ICSs on growth. But this can be confounded by factors such as, changes in asthma therapy, systemic use of steroids, pubertal changes, and normal short-term changes in growth rate.

Most of the earlier studies assessing the effect of ICSs on growth conducted were primary efficacy and safety studies with major limitations in their design to evaluate growth as a safety end point. In 2001, the U.S. Food and Drug Administration (FDA) issued guidelines on the study design and methodology for orally inhaled and intranasal corticosteroids for evaluation of their effects on growth in children [46]. The new guidelines recommended a prepubertal, Tanner stage 1, [37] mild, persistent asthma subject population and a placebo-controlled study design with a 16week baseline growth velocity data collection period, a double-blind 48-week treatment period, a 8-week follow up period, and repeated stadiometry measurements.

\section{Beclometasone Dipropionate (BDP)}

The Dutch Paediatric Asthma Study Group, comparing BDP with salmeterol showed that children treated with BDP at $200 \mu \mathrm{g}$ twice daily showed significantly slower growth rates than those treated with salmeterol at $50 \mu \mathrm{g}$ twice daily 
[47]. In an open label randomized study of prepubescent children that were treated with HFA-BDP at 100-200 $\mu \mathrm{g}$ /day or CFC-BDP at $200-400 \mu \mathrm{g} / \mathrm{day}$, the HFA-BDP group showed a similar, dose-dependent effect on growth from baseline compared with the CFC-BDP group. Results from these studies indicate that BDP may be associated with growth suppression. This little difference in level of effect on growth between the CFC- BDP and HFA-BDP despite large differences in lung delivery of CFC-BDP (4-7\%) versus HFA-BDP $(55-60 \%)$ may be caused by the high oral bioavailability of BDP [48]. In a recent randomized doubleblind placebo-controlled trial, TREXA study, involving 5- to 18-year-old patients with mild persistent asthma, linear growth was measured in two groups receiving regular therapy with $40 \mu \mathrm{g}$, twice daily of BDP-HFA; one group receiving rescue $\mathrm{BDP}$ plus albuterol only; and the other group receiving rescue albuterol only. Compared with the rescue albuterol group, linear growth was $1.1 \mathrm{~cm}$ less in both groups using regular twice daily $\mathrm{BDP}$, whereas no significant difference was seen in the BDP plus albuterol rescue group [49]. Another study, further examining the potential effects of ICS on growth in infants and toddlers, indicated no reduction in mean linear growth rates when a MDI-BDP inhaler was administered at a dosage of 200 $\mu \mathrm{g} /$ day [50].

\section{Budesonide (BUD)}

In the Steroid Treatment As Regular Therapy in Early Asthma study which was a randomised, double-blind trial in 7241 patients from 32 countries to assess the effects of budesonide in patients who had mild persistent asthma for less than 2 years and who had not had previous regular treatment with glucocorticoids, BUD at $200 \mu \mathrm{g}$ administered daily via a DPI was shown to reduce the growth of children younger than 11 years of age with persistent asthma over 3 years of treatment compared with placebo, with the greatest reduction in growth occurring in the $1^{\text {st }}$ year of treatment and less pronounced but significant reductions in growth during each subsequent year [51]. The reduction in growth was greatest in the first year of treatment $(0.58 \mathrm{~cm})$ than years 2 and $3(0.43 \mathrm{~cm}$ and $0.33 \mathrm{~cm}$, respectively). Additionally, growth rate was significantly lower in the BUD group compared with the placebo group in children 5-15 years of age at randomization. No dose-related effect was noted between subjects who received BUD at $200 \mu \mathrm{g}$ daily (subjects less than 11 years of age at randomization) and those who received BUD at $400 \mu \mathrm{g}$ daily (subjects more than 11 years of age at randomization) [57]. The CAMP study was designed to evaluate whether continuous, long-term treatment (over a period of four to six years) with either an inhaled corticosteroid (budesonide) or an inhaled noncorticosteroid drug (nedocromil) safely produces an improvement in lung growth when compared with treatment for symptoms only (with albuterol and, if necessary, prednisone, administered as needed). Results from the CAMP study showed that BUD at $200 \mu \mathrm{g}$ treatment administered twice daily via a Turbohaler was associated with a lower height after 4-6 years of treatment and slower growth velocity during the $1^{\text {st }}$ year of treatment compared with nedocromil at $8 \mathrm{mg}$ twice daily or placebo [52]. However, subjects reaching pubertal age at the completion of this study limited clear interpretation of the results. The Helsinki Early Intervention Childhood Asthma study investigated the effect of inhaled BUD-DPI in pre-pubertal children with newly diagnosed asthma [53]. In this study, the "continuous" BUD group received BUD at a dose of $400 \mu \mathrm{g}$ twice daily for the $1^{\text {st }}$ month, and then BUD $200 \mu \mathrm{g}$ twice daily for 5 months, followed by BUD $100 \mu \mathrm{g}$ twice daily for 12 months. The "as-needed" BUD/placebo group received BUD at a dose of $400 \mu \mathrm{g}$ twice daily for the $1^{\text {st }}$ month and BUD $200 \mu \mathrm{g}$ twice daily for 5 months, followed BUD as needed for exacerbations for 12 months. A third group received $10 \mathrm{mg}$ of disodium cromoglycate (DSCG) three times a day for 18 months. From baseline to 6 months, the mean standing height velocity in both BUD treatment groups was slower than that in the DSCG group. Height velocity increased in both BUD groups from months 7-18, while the as-needed group showed more rapid catch-up growth and a higher growth velocity compared with the continuous BUD group. Height velocity was higher in the DSCG group after 18 months of treatment than both the BUD treatment groups.

In a randomized open-label parallel group study of 52 pre-pubertal children to assess the relationship between short-term lower leg and 1-yr height increase in children with asthma treated with inhaled budesonide $200 \mu \mathrm{g}$ once daily in the morning or montelukast $5 \mathrm{mg}$ once daily, length of the lower leg and height were measured by knemometry and stadiometry respectively, at study entry and after 2, 4, $12,20,28,36,44$ and 52 weeks. Lower leg and height growth rates were significantly lower in the budesonide than in the montelukast group. Mean 2-weeks lower leg growth rate was $0.17 \mathrm{~mm} /$ week in the budesonide and $0.39 \mathrm{~mm} /$ week in the montelukast treated children $(\mathrm{p}=0.02)$. Mean 1-year height growth rate was $5.51 \mathrm{~cm} /$ year in the budesonide and 6.51 $\mathrm{cm} /$ year in the montelukast group [54]. A recent study by Zeiger et al. looked at changes in height, weight, and head circumference during the use of either placebo, intermittent nebulized BUD (1.0 mg at night), or daily nebulized BUD ( $0.5 \mathrm{mg}$ twice daily), over the course of a year in preschool children between 12 and 53 months of age and found that the changes were not significant [55].

\section{BUD and Adult Height}

Most studies conducted to date have indicated that growth suppression with ICS is transient, and children treated with ICS for asthma attain a final adult height within the expected normal range [56]. A follow-up trial of the CAMP study, however, showed that the decrease in height during the 4.3 years of BUD at a dose of $200 \mu \mathrm{g}$ twice daily versus placebo was significant and remained significant for an additional 4.8 years after the CAMP trial [57]. This height decrease was observed in girls $(1.7 \mathrm{~cm})$ but not in boys $(0.3$ cm only; insignificant). An update to the CAMP study was published in 2012 [58], which showed that the mean adult height was $1.2 \mathrm{~cm}$ lower in the BUD group than in the placebo group $(\mathrm{P}=0.001)$ and was $0.2 \mathrm{~cm}$ lower in the nedocromil group than in the placebo group $(\mathrm{P}=0.61)$. A larger daily dose of inhaled glucocorticoid in the first 2 years was associated with a lower adult height $(-0.1 \mathrm{~cm}$ for each microgram per kilogram of body weight $)(\mathrm{P}=0.007)$. The reduction in adult height in the BUD group as compared with the placebo group was similar to that seen after 2 years of 
treatment $(-1.3 \mathrm{~cm})$. During the first 2 years, decreased growth velocity in the BUD group occurred primarily in prepubertal participants. The authors concluded that, the initial decrease in attained height associated with the use of inhaled glucocorticoids in pre-pubertal children persisted as a reduction in adult height, although the decrease was not progressive or cumulative [58].

\section{Fluticasone Propionate (FP)}

In a study in children with persistent asthma in which subjects received FP at $100 \mu \mathrm{g}$ twice daily via DPI or nedocromil sodium at $8 \mathrm{mg} /$ day via MDI, both groups were shown to have similar growth rates. Adjusted mean growth rates were $6.1 \mathrm{~cm} /$ year with $\mathrm{FP}$ and $5.8 \mathrm{~cm} /$ year with nedocromil [59]. Treatment with FP-MDI at $50 \mu \mathrm{g}$ twice daily or $125 \mu \mathrm{g}$ twice daily for 6 months has also shown a lack of dose-dependent growth suppression in a study of young infants with recurrent wheezing [60]. In a doubleblind, randomized, parallel-group, multicenter study, 325 prepubescent children with persistent asthma and normal growth rates were treated with placebo or inhaled fluticasone propionate powder $50 \mu \mathrm{g}$ or $100 \mu \mathrm{g}$ administered twice daily by a breath-actuated device for 1 year. Growth was evaluated monthly, whereas other safety variables and pulmonary function were evaluated periodically. The prepubescent patients showed no statistically significant differences in mean height, mean growth velocity, or mean skeletal age between any of the treatment groups at any time [61]. In contrast to these earlier studies, results from the Prevention of Early Asthma in Kids study in which children who were at high risk for asthma, received FP at $88 \mu \mathrm{g}$ twice daily with an Aero-Chamber spacer and a face mask or placebo for the first 2 years and then discontinued ICS treatment in the $3^{\text {rd }}$ year (observation year) showed that after 2 years, subjects in the FP group were significantly shorter than subjects in the placebo group. In a more recent study, intermittent treatment with high dose FP (750 $\mu \mathrm{g}$ twice daily) starting at the onset of an upper respiratory tract infection (recurrent wheezing) was associated with slowing of growth compared with placebo in children 1-6 years of age [62].

\section{Mometasone Furoate (MF)}

Two studies have examined the growth effects of MF in children with asthma $[63,64]$. In the first study, treatment with MF-DPI at $100 \mu \mathrm{g} /$ day in the morning did not have any significant effect on growth velocity compared to placebo [69]. However, higher doses of MF-DPI (200 $\mu \mathrm{g}$ daily in the morning) did significantly reduce growth velocity compared with placebo. In the second study, children with persistent asthma receiving MF-MDI at $100 \mu \mathrm{g}$ daily in the evening did not exhibit any effect on growth velocity versus placebo [64]. The use of a daily dose of $100 \mu \mathrm{g}$ of MF-DPI in children aged 4-9 years with mild persistent asthma is supported by the lack of significant difference in growth velocity and absence of drug-related adreno-cortical effects [64]. However, the relatively small sample size was a limitation in both of these studies. These results suggest that at higher doses MF may have an effect on growth.

\section{Ciclesonide (CIC)}

A study of CIC in pre-pubertal children who were randomized to three groups, treatment with placebo, CICHFA-MDI at $40 \mu \mathrm{g}$ daily or CIC-HFA-MDI at $160 \mu \mathrm{g}$ daily [65]. There was no detectable effect on growth velocity in either CIC treatment group versus placebo after 52 weeks of treatment. In a 12-week multicenter, double-blind, placebocontrolled, study designed primarily for efficacy, children (n $=1073 ; 6-11$ years) with persistent asthma were randomized to CIC at 40,80 , or $160 \mu \mathrm{g}$ (daily in the afternoon) via MDI or MDI plus spacer had no effect on growth was detected by stadiometry for any of the doses or delivery methods [66]. The above two studies met the recommendations of the current FDA advisory on evaluating the effects of ICS on growth.

\section{Flunisolide (FLU)}

In a double-blind, placebo-controlled study, meeting the recommendations of the current FDA guidance on evaluating the effects of ICS on growth, 218 prepubescent (Tanner Stage 1) children with mild persistent asthma ranging in age from 4 to 10 years were randomized to 2 puffs FLU-HFA twice daily ( $85 \mu \mathrm{g} /$ puff) or placebo for 52 weeks. Height was assessed by stadiometry at each visit. At the end of doubleblind treatment, mean growth velocity was $6.01 \pm 1.84$ $\mathrm{cm} / 52$ weeks for FLU-HFA and $6.19 \pm 1.30 \mathrm{~cm} / 52$ weeks for placebo ( $\mathrm{p}$ value not significant). Mean advancement in bone age during the 1-year study was similar for the 2 groups. This study indicated that in children with persistent asthma, FLU-HFA had no deleterious effect on growth or bone maturation1 year at the highest approved dose [67].

\section{BUD vs FP}

One study in children 4-12 years of age with moderateto-severe asthma, who received either FP-DPI at $200 \mu \mathrm{g}$ twice daily or BUD-DPI at $400 \mu \mathrm{g}$ twice daily for 20 weeks showed that subjects in the BUD group grew $6.2 \mathrm{~mm}$ less than those treated with FP [68]. In contrast, other studies have indicated that FP and BUD have similar effects on growth $[69,70]$. No significant change in height velocity was seen between the treatment groups, in a study of 100 children 4-11.5 years of age, 51 boys and 49 girls, with moderate persistent asthma who were randomized to FPMDI at $125 \mu \mathrm{g}$ twice daily or BUD-MDI at $200 \mu \mathrm{g}$ twice daily for 52 weeks [69]. In a study of children with moderate asthma aged, 7-13 years suggested that BUD at a dose of 400 $\mu \mathrm{g} /$ day or FP $250 \mu \mathrm{g} /$ day no difference in growth rate was seen compared to children in the control group [70].

\section{BUD vs CIC}

In children with mild persistent asthma 6-11 years of age were randomized to BUD at $400 \mu \mathrm{g}$ daily (via Turbohaler) or $\mathrm{CIC}$ at $60 \mu \mathrm{g}$ (via HFA-MDI plus spacer) daily in the evening [71]. Stadiometry was performed in a subset of subjects. At end of the study, at 12 weeks there was significantly less growth suppression in the CIC group 
versus the BUD group and there was less evidence of adrenal suppression in the CIC group. However, a Cochrane review comparing the efficacy and side effect profile of CIC with other ICS did not show an advantage of CIC over other molecules [72].

\section{Montelukast vs FLP}

Children 6-14 years of age, with mild persistent asthma were treated with montelukast at $5 \mathrm{mg}$ daily or FP (via MDI) at $100 \mu \mathrm{g}$ twice daily for one year, in the Montelukast Study of Asthma in Children (MOSAIC study) [73]. The overall growth suppression was more in the FP group versus the montelukast group over the 12 months of treatment.

\section{ICS in Combination with Long-Acting $\beta 2$-Agonists}

In the Pediatric Asthma Controller Trial, 285 children (ages 6-14 years) with mild-moderate persistent asthma were randomized to: fluticasone $100 \mu \mathrm{g}$ twice daily, fluticasone $100 \mu \mathrm{g} / \mathrm{salmeterol} 50 \mu \mathrm{g}$ in the morning and salmeterol 50 $\mu \mathrm{g}$ in the evening, and montelukast $5 \mathrm{mg}$ in the evening. The observed growth over 48 weeks in all the three groups was comparable, with no statistically significant difference between the groups fluticasone: $5.3 \mathrm{~cm}$; salmetrol and fluticasone combination: $5.3 \mathrm{~cm}$; montelukast: $5.7 \mathrm{~cm}$ [74].

In a multicenter, randomized, parallel-group, doubleblind study comparing salmeterol/FLP 50/100 $\mu \mathrm{g}$ twice a day compared with FLP $200 \mu \mathrm{g}$ twice a day in children with symptomatic asthma, no significant differences were found, after 26 weeks of treatment between either groups on growth in children aged 6-16 yrs [75].

In a randomised double-blind, placebo-controlled crossover study to study impact of beta 2 agonist in reducing dose of ICS, and to study effects on short term growth and collagen turnover, formoterol was added to half the glucocorticoid dose in children with asthma treated with inhaled BUD over two six-week periods. Mean lower leg growth rate was $0.14 \mathrm{~mm} /$ week $(p=0.02)$ lower in children on BUD $200 \mu \mathrm{g}$ twice daily than on that during the period of treatment with formoterol and BUD. Identical statistically significant effects on markers of collagen turnover were found, whereas inflammation markers and asthma control did not vary significantly between the two periods [76].

\section{ADRENAL AXIS SUPPRESSION DUE TO ICS}

The time of administration of ICS and its impact on growth has also been studied. In a study among children 5.6 -12.5 years of age with intermittent asthma, lower leg growth rate after treatment with $400 \mu \mathrm{g}$ of BUD-MDI twice daily (administered with a Nebuhaler spacer) for 4 weeks was significantly lower whereas treatment with $800 \mu \mathrm{g}$ of BUDMDI once daily in the morning did not suppress growth, suggesting evening dosing may have a greater risk of growth suppression [77]. Children who have severe asthma requiring consistent high dose ICS therapy [78] or who are receiving corticosteroids for coexisting diseases(e.g., dermal for eczema or rheumatological diseases) are at an increased risk for HPA axis suppression. If there is a clinical suspicion of adrenal axis suppression, and if morning plasma cortisol levels are less than $10 \mu \mathrm{g} / \mathrm{decilitre}$, a low-dose adrenocortico- trophin (ACTH) test is indicated [79]. Reduced cortisol responsiveness to low-dose ACTH suggests the need of additional hydrocortisone for significant illness or injury.

The 2010 Global Initiative for Asthma guidelines have now delineated the appropriate asthma treatment regimen for preschool children aged less than 5 years [80]. It is essential that these children and their families receive appropriate education about asthma, alter their environment to minimize asthma triggers, and then, if that approach alone is not successful, to proceed with a therapeutic regimen that initially includes inhaled beta agonists, augmented with increasing doses of ICS to optimize the patient's asthma management. After the patient has attained control for 3 months, the ICS dose is to be gradually decreased until the minimum necessary dose to maintain control is reached.

\section{BONE METABOLISIM, VITAMIN D SUPPLEMEN- TATION AND FRACTURES}

Studies have been done to investigate the effect of inhaled steroids on bone metabolism, and whether vitamin D supplementation ameliorates these effects. Seventy-five children with new asthma were enrolled into BUD, FLP or cromoglycate treatment groups. The initial BUD dose was $800 \mu \mathrm{g} /$ day and $400 \mu \mathrm{g} /$ day after two months. The initial FLP doses were 500 and subsequently $200 \mu \mathrm{g} /$ day. Bone turnover markers were measured before treatment and after 2 and 4 months of therapy. In the steroid treated children whose height standard deviation score decreased during the first 12 months of therapy, bone formation markers serum osteocalcin (OC) decreased by $20 \%$ and carboxyterminal propeptide of type I procollagen (PICP) decreased by $21 \%$, during the initial 4 months both significantly. In the children who did not have growth suppression, the changes were not significant: $-4 \%$ in OC and $+13 \%$ in PICP respectively. In children who had evidence of adrenal axis suppression (on the basis of a low-dose ACTH stimulation test), OC decreased more $(23 \%, \mathrm{p}<0.01)$ than in those with normal adrenocortical function $(10 \%, \mathrm{p}=0.06)$ [81]. Population based studies of children aged 4-17 years in the UK estimated incidence rates of fracture among children 4-17 years old taking ICS, have suggested, that the increased risk of fracture is probably a result of the underlying illness, rather than being directly attributable to ICS therapy [82]. In a study supplementation of 25-hydroxyvitamin D did not affect short-term growth or markers of bone turnover in children with asthma treated with inhaled dry-powder BUD $400 \mu \mathrm{g}$ daily [83].

\section{CONCLUSION}

The risk of adverse effects on growth of inhaled corticosteroids can be minimized by using the minimum effective dosage, decreasing systemic availability of the drug through careful selection of the inhalation device and proper technique, the concomitant use of alternative antiinflammatory agents and, appropriate choice of the ICS medication with least effect on growth. Current evidence from the studies reviewed in this article indicates that ICS treatments for asthma may differ in their effects on growth. However, additional, rigorously-designed studies may be warranted to further clarify the effects of ICS on the degree 
of suppression of growth. The 1-year studies show a small, dose-dependent effect of most ICS on childhood growth, with some differences across various ICS molecules. Some ICS types, at the doses studied, did not show an effect on childhood growth when rigorous study designs were used. Most studies did not conform completely with the FDA guidance. The evidence of childhood ICS use on final adult height are conflicting, but one recent study by Kelly et al. showed such an effect. In spite of these measurable effects of ICS on the growth, it is important to recall that the safety profile of all ICS preparations, which focus antiinflammatory effects on the lung, is markedly better than the oral glucocorticoids.

\section{CONFLICT OF INTEREST}

The author confirms that this article content has no conflict of interest.

\section{ACKNOWLEDGEMENTS}

Declared none.

\section{REFERENCES}

[1] Expert panel report 3: guidelines for the diagnosis and management of asthma Bethesda, MD: National Heart, Lung and Blood Institute, August 2007. http://www.nhlbi.nih.gov/files/docs/guidelines/asthgd ln.pdf; accessed on 05 September 2014.

[2] Umland SP, Schleimer RP, Johnston SL. Review of the molecular and cellular mechanisms of action of glucocorticoids for use in asthma. Pulm Pharmacol Ther 2002; 15: 35-50.

[3] Pelaia G, Vatrella A, Cuda G, Maselli R, Marsico SA. Molecular mechanisms of corticosteroid actions in chronic inflammatory airway diseases. Life Sci 2003; 72: 1549-61.

[4] Chanez P, Bourdin A, Vachier I, Godard P, Bousquet J, Vignola AM. Effects of inhaled corticosteroids on pathology in asthma and chronic obstructive pulmonary disease. Proc Am Thorac Soc 2004; 1: $184-90$.

[5] Lundgren R, Soderberg M, Horstedt P, Stenling R. Morphological studies of bronchial mucosal biopsies from asthmatics before and after ten years of treatment with inhaled steroids. Eur Respir J 1988; 1: 883-9.

[6] Feltis BN, Wignarajah D, Reid DW, Ward C, Harding R, Walters EH. Effects of inhaled fluticasone on angiogenesis and vascular endothelial growth factor in asthma. Thorax 2007; 62: 314-9.

[7] Pedersen S. Clinical safety of inhaled corticosteroids for asthma in children: An update of long-term trials. Drug Saf 2006; 29: 599612 .

[8] Allen DB. Effects of inhaled steroids on growth, bone metabolism, and adrenal function. Adv Pediatr 2006; 53: 101-10.

[9] Allen DB. Growth suppression by glucocorticoid therapy. In: Rosenfield RL, Ed. Growth and Growth Disorders. WB Saunders Company: PA, USA 1996; pp. 699-718.

[10] Allen DB. Growth impairment related to severe asthma. In: Szefler S, Leung D, Eds. Severe Asthma: Pathogenesis and Clinical Management. NY, USA: Marcel Dekker Inc. 2001; pp. 505-32.

[11] Camargos PA, Lasmar LM. Effects of beclomethasone and factors related to asthma on the growth of pre pubertal children. Respir Med 2010; 104: 951-6.

[12] Mortimer KJ, Tata LJ, Smith et al. Oral and inhaled corticosteroids a case control study. Thorax 2006; 61: 405-8.

[13] Pedersen S. Do inhaled corticosteroids inhibit growth in children? Am J Respir Crit Care Med 2001; 164: 521-35.

[14] Derendorf H. Pharmacokinetic and pharmacodynamics properties of inhaled corticosteroids in relation to efficacy and safety. Respir Med 1997; 91: 22-8.

[15] Pedersen S, O'Byrne P. A comparison of the efficacy and safety of inhaled corticosteroids in asthma. Allergy 1997; 52: 1-34.
[16] Derendorf H, Nave R, Drollmann A, Cerasoli F, Wurst W. Relevance of pharmacokinetics and pharmacodynamics of inhaled corticosteroids to asthma. Eur Respir J 2006; 28: 1042-50.

[17] Burgt VJA, Busse WW, Martin RJ, Szefler SJ, Donnell D. Efficacy and safety overview of a new inhaled corticosteroid, QVAR (hydrofluoroalkane-beclomethasone extrafine inhalation aerosol), in asthma. J Allergy Clin Immunol 2000; 106: 1209-26.

[18] Pritchard JN. The influence of lung deposition on clinical response J Aerosol Med 2001; 14: S19-S26.

[19] Balter MS, Adams SG, Chapman KR. Inhaled beclomethasone dipropionate improves acoustic measures of voice in patients with asthma. Chest 2001; 120: 1829-34.

[20] Borgstrom L. The pharmacokinetics of inhaled hydrofluoroalkane formulations. J Allergy Clin Immunol 1999; 104: S246-9.

[21] Toogood JH, Jennings B, Greenway RW, Chuang L. Candidiasis and dysphonia complicating beclomethasone treatment of asthma. J Allergy Clin Immunol 1980; 65: 145-53.

[22] Fuller R. The Diskus: A new multi-dose powder device -efficacy and comparison with Turbuhaler. J Aerosol Med 1995; 8: S11-7.

[23] Agertoft L, Pedersen S, Nikander K. Drug delivery from the Turbuhaler and Nebuhaler pressurized metered dose inhaler to various age groups of children with asthma. J Aerosol Med 1999; 12: 16169 .

[24] Rohatagi S, Derandorf $\mathrm{H}$, Zech $\mathrm{K}$, et al. PK/PD of inhaled corticosteroids: the risk/benefit of inhaled ciclesonide [abstract]. J Allergy Clin Immunol 2003; 111(2 Suppl): 598.

[25] Derendorf H, Hochhaus G, Meibohm B, Mollmann H, Barth J. Pharmacokinetics and pharmacodynamics of inhaled corticosteroids. J Allergy Clin Immunol 1998; 101 (4 Pt 2): S440-6.

[26] Zeidler M, Corren J. Hydrofluoroalkane formulations of inhaled corticosteroids for the treatment of asthma. Treat Respir Med 2004; 3: $35-44$

[27] Leach CL, Davidson PJ, Boudreau RJ. Improved airway targeting with the CFC-free HFA-beclomethasone metered-dose inhaler compared with CFC-beclomethasone. Eur Respir J 1998; 12: 134653.

[28] Leach CL, Davidson PJ, Hasselquist BE, Boudreau RJ. Lung deposition of hydrofluoroalkane-134a beclomethasone is greater than that of chlorofluorocarbon fluticasone and chlorofluorocarbon beclomethasone: a cross-over study in healthy volunteers. Chest 2002; 122: 510-16.

[29] Leach CL, Bethke TD, Boudreau RJ, et al. Two-dimensional and three-dimensional imaging show ciclesonide has high lung deposition and peripheral distribution: a nonrandomized study in healthy volunteers. J Aerosol Med 2006; 19: 117-26.

[30] Newman S, Salmon A, Nave R, Drollmann A. High lung deposition of $99 \mathrm{mTc}$-labeled ciclesonide administered via HFAMDI to patients with asthma. Respir Med 2006; 100: 375-84.

[31] Rohatagi S, Arya V, Zech K, et al. Population pharmacokinetics and pharmacodynamics of ciclesonide. J Clin Pharmacol 2003; 43 : 365-78.

[32] Derendorf H, Hochhaus G, Rohatagi S, et al. Pharmacokinetics of triamcinolone acetonide after intravenous, oral, and inhaled administration. J Clin Pharmacol 1995; 35: 302-5.

[33] Ryrfeldt A, Andersson P, Edsbacker S, Tonnesson M, Davies D, Pauwels R. Pharmacokinetics and metabolism of budesonide, a selective glucocorticoid. Eur J Respir Dis Suppl 1982; 122: 86-95.

[34] Nave R, Bethke TD, van Marle SP, Zech K. Pharmacokinetics of [14C] ciclesonide after oral and intravenous administration to healthy subjects. Clin Pharmacokinet 2004; 43: 479-86.

[35] Daley-Yates PT, Price AC, Sisson JR, Pereira A, Dallow N. Beclomethasone dipropionate: Absolute bioavailability, pharmacokinetics and metabolism following intravenous, oral, intranasal and inhaled administration in man. Br J Clin Pharmacol 2001; 51: 400-9.

[36] Dickens GR, Wermeling DP, Matheny CJ, et al. Pharmacokinetics of flunisolide administered via metered dose inhaler with and without a spacer device and following oral administration. Ann Allergy Asthma Immunol 2000; 84: 528-32.

[37] Sharpe M, Jarvis B. Inhaled mometasone furoate: a review of its use in adults and adolescents with persistent asthma. Drugs 2001; 61: 1544 .

[38] Nave R, Zech K, Bliesath H, Bethke T. Differences between pharmacokinetics of ciclesonide-active principle and budesonide following repeated dose inhalations. Eur Respir J 2003; 22: 33. 
[39] Lipworth BJ, Jackson CM. Safety of inhaled and intranasal corticosteroids: Lessons for the new millennium. Drug Saf 2000; 23: 11-33.

[40] Miller-Larsson A, Axelsson B-O, Brattsand R, Edsbacker S, Ingelf J. Relative lipophilicity of budesonide, fluticasone propionate, mometasone furoate, and ciclesonide. Preference of variable lipophilicity in airways versus systemic compartment. Am J Respir Crit Care Med 2003; 167: A773.

[41] Rohatagi S, Arya V, Zech K, et al. Population pharmacokinetics and pharmacodynamics of ciclesonide. J Clin Pharmacol 2003; 43: 365-78.

[42] Chopra D, Bhandari B, Vardhan N. Ciclesonide - A Novel Corticosteroid for the Management of Asthma. Curr Clin Pharmacol 2012. [Epub ahead of print]

[43] Sastre J, Mosges R. Local and systemic safety of intranasal corticosteroids. J Investig Allergol Clin Immunol 2012; 22: 1-12.

[44] Verberne AA, Frost C, Roorda RJ, van der Laag H, Kerrebijn KF. One year treatment with salmeterol compared with beclomethasone in children with asthma. The Dutch Paediatric Asthma Study Group. Am J Respir Crit Care Med 1997; 156(3 Pt 1): 688-95.

[45] Agertoft L, Pedersen S. Short-term lower-leg growth rate and urine cortisol excretion in children treated with ciclesonide. J Allergy Clin Immunol 2005; 115: 940-5.

[46] Food and Drug Administration. Orally inhaled and intranasal corticosteroids: Evaluation of the effects on growth in children. 2007.

www.fda.gov/downloads/Drugs/GuidanceComplianceRegulatoryIn formation/Guidances/ucm 071968.pdf. Accessed on 05 September 2014.

[47] Verberne AA, Frost C, Roorda RJ, et al. One year treatment with salmeterol compared with beclomethasone in children with asthma. The Dutch Paediatric Asthma Study Group. Am J Respir Crit Care Med 1997; 156: 688-95.

[48] Pedersen S, Warner J, Wahn U, et al. Growth, systemic safety, and efficacy during 1 year of asthma treatment with different beclomethasone dipropionate formulations: An open label, randomized comparison of extra fine and conventional aerosols in children. Pediatrics 2002; 109: e92.

[49] Martinez FD, Chinchilli VM, Morgan WJ, et al. Use of beclomethasone dipropionate as rescue treatment for children with mild persistent asthma (TREXA): A randomised, double-blind, placebo-controlled trial. Lancet 2011; 377(9766): 650-7.

[50] Teper AM, Kofman CD, Maffey AF, et al. Effect of inhaled beclomethasone dipropionate on pulmonary function, bronchial reactivity and longitudinal growth in infants with bronchial asthma. Pediatric Res 1996; 39: 369

[51] Pauwels RA, Pedersen S, Busse WW, et al. Early intervention with budesonide in mild persistent asthma: A randomised, double-blind trial. Lancet. 2003; 361(9363): 1071-6.

[52] Szefler S, Weiss S, and Tonascia J. Long-term effects of budesonide or nedocromil in children with asthma. The Childhood Asthma Management Program Research Group. N Engl J Med 2000; 343: 1054-63.

[53] Turpeinen M, Nikander K, Pelkonen AS, et al. Daily versus asneeded inhaled corticosteroid for mild persistent asthma (The Helsinki early intervention childhood asthma study). Arch Dis Child 2008; 93: 654-9.

[54] Gradman J, and Wolthers OD. A randomized trial of lower leg and height growth in children with asthma treated with inhaled budesonide from a new dry powder inhaler. Pediatr Allergy Immunol 2010; 21: e206-12.

[55] Zeiger RS, Mauger D, Bacharier LB, et al. Daily or intermittent budesonide in preschool children with recurrent wheezing. N Engl J Med 2011; 365: 1990-2001.

[56] Agertoft L, Pedersen S. Effect of long-term treatment with inhaled budesonide on adult height in children with asthma. N Engl J Med 2000; 343: 1064-9.

[57] Strunk RC, Sternberg AL, Szefler SJ, et al. Long-term budesonide or nedocromil treatment, once discontinued, does not alter the course of mild to moderate asthma in children and adolescents. $\mathbf{J}$ Pediatr 2009; 154: 682-7.

[58] Kelly HW, Sternberg AL, Lescher R, et al. Effect of inhaled glucocorticoids in childhood on adult height. N Engl J Med 2012; 367: 904-12.
[59] Roux C, Kolta S, Desfougeres JL, et al. Long-term safety of fluticasone propionate and nedocromil sodium on bone in children with asthma. Pediatrics 2003; 111: e706-13.

[60] Teper AM, Colom AJ, Kofman CD, et al. Effects of inhaled fluticasone propionate in children less than 2 years old with recurrent wheezing. Pediatr Pulmonol 2004; 37: 111-5.

[61] Allen DB, Bronsky EA, LaForce CF, et al. Growth in asthmatic children treated with fluticasone propionate. Fluticasone Propionate Asthma Study Group. J Pediatr 1998; 132: 472-7.

[62] Ducharme FM, Lemire C, Noya FJ, et al. Preemptive use of highdose fluticasone for virus-induced wheezing in young children. $\mathrm{N}$ Engl J Med 2009; 360: 339-53.

[63] Skoner DP, Murphy K, Lemanske R, et al. Once-daily dosing of $100 \mu \mathrm{g}$ mometasone furoate has no effect on growth velocity in children with asthma. Ann Allergy Asthma Immunol 2009; 102: A53.

[64] Skoner DP, Dunn M, Lee T. Effects of inhaled mometasone furoate on growth velocity and adrenal function: A placebo controlled trial in children 4-9 years old with mild persistent asthma. J Asthma 2011; 48: 848-59.

[65] Skoner DP, Maspero J, Banerji D. Assessment of the longterm safety of inhaled ciclesonide on growth in children with asthma. Pediatrics 2008; 121: e1-14

[66] Pedersen S, Potter P, Dachev S, et al. Efficacy and safety of three ciclesonide doses $v s$ placebo in children with asthma: The RAINBOW study. Respir Med 2010; 104: 1618-28.

[67] Bensch GW, Greos LS, Gawchik S, et al. Linear growth and bone maturation are unaffected by 1 year of therapy with inhaled flunisolide hydrofluoroalkane in prepubescent children with mild persistent asthma: A randomized, double blind, placebo-controlled trial. Ann Allergy Asthma Immuno 2011; 107: 323-9.

[68] Ferguson AC, Spier S, Manjra A, Versteegh FG, Mark S, Zhang P. Efficacy and safety of high-dose inhaled steroids in children with asthma: A comparison of fluticasone propionate with budesonide. J Pediatr 1999; 134: 422-7.

[69] Acun C, Tomac N, Ermis B, and Onk G. Effects of inhaled corticosteroids on growth in asthmatic children: A comparison of fluticasone propionate with budesonide. Allergy Asthma Proc 2005; 26: 204-6.

[70] Altintas DU, Karakoc GB, Can S, Yilmaz M, Kendirli SG. The effects of long term use of inhaled corticosteroids on linear growth, adrenal function and bone mineral density in children. Allergol Immunopathol (Madr) 2005; 33: 204-9.

[71] von Berg A, Engelstatter R, Minic P, et al. Comparison of the efficacy and safety of ciclesonide 160 microg once daily vs.budesonide 400 microg once daily in children with asthma. Pediatr Allergy Immunol 2007; 18: 391-400.

[72] Kramer S, Rottier BL, Scholten RJ, Boluyt N. Ciclesonide versus other inhaled corticosteroids for chronic asthma in children. Cochrane Database Syst Rev 2013; 2: CD010352

[73] Garcia Garcia ML, Wahn U, Gilles L, et al. Montelukast, compared with fluticasone, for control of asthma among 6- to 14-year-old patients with mild asthma: The MOSAIC study. Pediatrics 2005; 116: 360-9.

[74] Sorkness CA, Lemanske RF Jr, Mauger DT, et al. Long-term comparison of 3 controller regimens for mild-moderate persisten childhood asthma: The Pediatric Asthma Controller Trial. J Allergy Clin Immunol 2007; 119: 64-72.

[75] Vaessen-Verbernevan, van den berg NJ, Nierop JC, et al. Combination therapy salmeterol/fluticasone versus doubling dose of fluticasone in children with asthma. Am J Respir Crit Care Med 2010; 182: 1221-7.

[76] Heuck C, Heickendorff L, Wolthers OD. A randomised controlled trial of short term growth and collagen turnover in asthmatics treated with inhaled formoterol and budesonide. Arch Dis Child 2000; 83: 334-9.

[77] Heuck C, Wolthers OD, Kollerup G, et al. Adverse effects of inhaled budesonide (800 micrograms) on growth and collagen turnover in children with asthma: A double-blind comparison of once-daily versus twice-daily administration. J Pediatr 1998; 133: 608-12.

[78] Todd GR, Acerini CL, Buck JJ, et al. Acute adrenal crisis in asthmatics treated with high-dose fluticasone propionate. Eur Respir J 2002; 19: 1207-9.

[79] Kannisto S, Korppi M, Remes K, Voutilainen R. Adrenal suppression, evaluated by a low dose adrenocorticotropin test, and 
growth in asthmatic children treated with inhaled steroids. J Clin Endocrinol Metab 2000; 85: 652-7.

[80] Global Initiative for Asthma. The global strategy for the diagnosis and management of asthma in children 5 years and younger. 2009. http://www.ginasthma.org/local/uploads/files/GINA_Under5_2009 CorxAug11.pdf Accessed on 05 September 2014.

[81] Kannisto S, Korppi M, Arikoski P, Remes K, Voutilainen R. Biochemical markers of bone metabolism in relation to adrenocortical and growth suppression during the initiation phase of inhaled steroid therapy. Paediatr Res 2002; 52: 258-62.

[82] Van Staa TP, Leufkens HG, Cooper C. Are inhaled corticosteroids associated with an increased risk of fracture in children? Osteoporos Int 2004; 15: 785-91.

[83] Schou AJ, Heuck C, Wolthers OD. Does vitamin D administered to children with asthma treated with inhaled glucocorticoids affect short-term growth or bone turnover? Pediatr Pulmonol 2003; 36: 399-404

(C) Jim Philip; Licensee Bentham Open.

This is an open access article licensed under the terms of the Creative Commons Attribution Non-Commercial License (http://creativecommons.org/licenses/by-nc/3.0/) which permits unrestricted, non-commercial use, distribution and reproduction in any medium, provided the work is properly cited. 